\title{
3. O MODELO EXPLANATÓRIO-CAUSAL DE ARISTÓTELES EM SEGUNDOS ANALÍTICOS II.8-10 E O CASO DAS SUBSTÂNCIAS HILEMÓRFICAS
}

https://doi.org/10.36592/9786581110369-03

Daniela Fernandes Cruz'

RESUMO: Nos Segundos Analíticos II.8-10, Aristóteles apresenta um modelo investigativo de descoberta da essência pela causa a partir de uma estrutura triádica: a demonstração silogística. Esse modelo explanatório-causal é colocado em prática em casos de processos naturais (e.g. eclipse, trovão) e, apesar de mencionadas, as substâncias sensíveis (e.g. homem) não são concretamente analisadas - algo que só se consolida nos livros centrais da Metafísica (mais especificamente, Z.17) a partir da análise hilemórfica. Além disso, em Segundos Analíticos II.9, Aristóteles apresenta uma restrição quanto ao domínio de aplicação do modelo: apenas os itens que possuem "causa diferente" (Ётвроv aĭtıov) são passíveis de análise nesses termos. Se, por um lado, o capítulo parece ser uma restrição ao caso específico das substâncias, não são explicitados quais itens possuem e quais não possuem "causa diferente". Desse modo, é suscitada a questão: teria Aristóteles previsto a aplicação do modelo explanatório-causal às substâncias hilemórficas quando da elaboração dos Segundos Analíticos, ou sua utilização na Metafísica representaria uma reformulação posterior? Neste cenário, temos pelo menos duas hipóteses interpretativas: (i) uma leitura restritiva (ou desenvolvimentista), em que as substâncias não teriam sido previstas; (ii) uma leitura não-restritiva, que se opõe à primeira ao defender que as substâncias já estariam previstas na elaboração dos Segundos Analíticos, e sua omissão se daria por economia argumentativa. 0 objetivo do presente trabalho é apresentar a hipótese não-restritiva como uma solução para

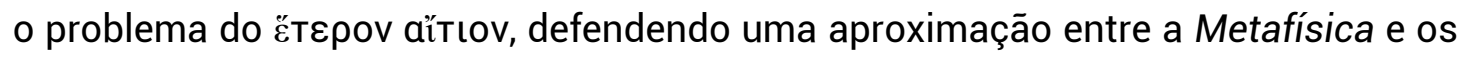
Segundos Analíticos.

palavras-chave: Aristóteles, causalidade, essência, silogismo

\footnotetext{
${ }^{1}$ Graduanda em Letras pela Universidade Federal de São Paulo (Unifesp). Bolsista de Iniciação Científica da Fundação de Amparo à Pesquisa do Estado de São Paulo (FAPESP). Endereço eletrônico: daniela.fernandes12@unifesp.br
} 


\section{6 | XXI Semana Acadêmica do PPG em Filosofia da PUCRS, Vol. 1}

\section{Introdução}

No livro II dos Segundos Analíticos (APo), Aristóteles apresenta um modelo de descoberta da essência pela causa a partir de uma estrutura triádica: a demonstração silogística. Para exemplificar seu modelo explanatório-causal, Aristóteles utiliza casos de processos naturais (e.g. eclipse, trovão) e, apesar de mencionadas, as substâncias sensíveis (e.g. homem) não são concretamente analisadas - algo que só se consolida nos livros centrais da Metafísica, mais especificamente em Z.17, através da análise hilemórfica. Além disso, o domínio de aplicação do modelo possui uma restrição, apresentada em APo II.9: apenas itens


demonstração silogística. No entanto, não são explicitados quais itens possuem e quais não possuem "causa diferente". Desse modo, é suscitada a questão: ao elaborar os Analíticos, Aristóteles já teria previsto a aplicação do seu modelo explanatório-causal às substâncias hilemórficas, ou sua utilização na Metafísica representaria uma reformulação posterior?

Essa questão foi interpretada de modo diverso pela literatura. Por um lado, intérpretes como Ross (1949), Goldin (1996) e Bronstein (2016) defendem que nos Analíticos é realizada uma distinção fundamental entre substâncias e atributos e, nesse contexto, apenas os atributos integrariam o domínio de aplicação do modelo. A Metafísica, assim, é tida como obra de maturidade de Aristóteles, representando uma reformulação do modelo original ao acrescentar a análise hilemórfica das substâncias. Essa hipótese, a qual chamaremos de hipótese desenvolvimentista ou restritiva, é confrontada por Charles (2000), Peramatzis (2011) e Zuppolini (2017), os quais endossam uma leitura não-restritiva do problema apresentado. Nesta, defende-se que a omissão das substâncias sensíveis em $A P o$ não ocorre sem evidências de que a análise hilemórfica já havia sido prevista, e uma aplicação concreta é dispensada tão somente por economia argumentativa. Ao estabelecer uma aproximação entre a Metafísica e os Analíticos, essa última hipótese nos parece

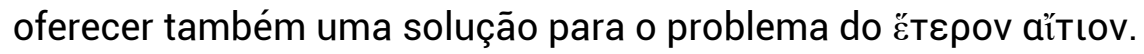

Com o objetivo de explorar essa possibilidade, esta comunicação será dividida em quatro seções: i) uma caracterização do modelo explanatório-causal de 
Aristóteles, tal qual apresentado em APo II.1-2 8-10 e Met. Z.17; ii) apresentação do

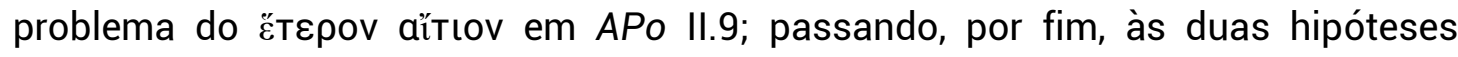
interpretativas iii) a leitura desenvolvimentista e iv) a leitura não-restritiva. Pretendemos, assim, mostrar de que modo cada hipótese busca solucionar a aparente inconsistência entre APo II.9 e Met. Z.17, e as vantagens de adotar uma leitura conciliatória nesse sentido.

\section{0 modelo explanatório-causal de Aristóteles em APo II.8-10 e Met. Z.17}

A presente seção se dedicará a uma breve análise do modelo explanatóriocausal $^{2}$ de Aristóteles, apresentado nos primeiros capítulos do livro II dos Segundos Analíticos, e retomado nos livros centrais da sua Metafísica. Partiremos das questões passíveis de investigação (APo II.1-2) à aplicação prática do modelo (APo II.8; Met. Z.17), comparando sua apresentação em ambos os tratados.

Uma vez que nos Analíticos, Aristóteles se ocupa da noção de conhecimento

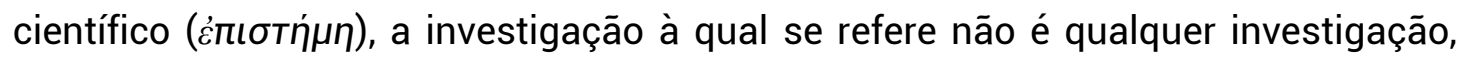
mas àquela propriamente científica, de modo que é imprescindível ao investigador adotar o ponto de partida correto. Nesse contexto, o livro II dos Segundos Analíticos é aberto com a introdução das questões passíveis de investigação, e em que ordem precisam estar dispostas:

O que se investiga é igual em número a tudo quanto conhecemos. Investigamos quatro coisas: [Q1] que, [Q2] por que, [Q3] se é, [Q4] o que é. Quando investigamos isto ou aquilo (considerando-o como uma mulplicidade), por exemplo: o sol sofre eclipse ou não? Investigamos que. Eis um sinal disso: tendo descoberto que sofre eclipse, detemo-nos; e se desde o início sabemos que se eclipsa, não investigamos se se eclipsa. (APo II.1 89b 23-29. trad. Angioni, 2002, com modificações)

Enquanto Q1 diz respeito ao conhecimento do fato, perguntando pela presença de um predicado em um sujeito (e.g.: saber que $S$ é $P$; saber que a lua (S)

\footnotetext{
${ }^{2}$ Utilizamos a terminologia de Peramatzis (2018).
} 


\section{8 | XXI Semana Acadêmica do PPG em Filosofia da PUCRS, Vol. 1}

sofre eclipse (P)), $\mathbf{Q} 2$ busca a causa ou a explicação de um predicado atribuir-se a um sujeito (e.g.: saber por que $S$ é $P$; saber por que a lua $(S)$ sofre eclipse $(P))$, Q3 pergunta pela existência de algo (e.g.: saber se S/P existe; se existe eclipse, se existe homem); por fim, Q4 busca uma definição ou essência de um dado item (e.g.: saber o que S/P é; o que é eclipse, o que é homem). Seguindo para o capítulo II, em 89b37-

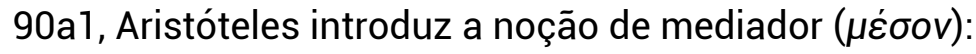

Quando investigamos o que ou se é de modo absoluto, estamos investigando se porventura há ou não há mediador da própria coisa; mas, por outro lado, quando investigamos o por que ou o que é, após ter conhecido ou que ou se é (ou em parte ou de modo absoluto), estamos investigando o que é o mediador. (...) Assim, decorre que, em todas as investigações, investiga-se ou se há mediador, ou o que é o mediador. Pois o mediador é a causa, e é ela que se investiga em todos esses casos. (APo II.2 89b37-90a1, 90a5-6, trad. Angioni, 2002, com modificações)

A novidade nesse capítulo é o tratamento do mediador - que se refere ao termo médio, comum às duas premissas do silogismo - como "causa" (90a6) e, consequentemente, a análise da causa por meio desta estrutura triádica ( $A$ se atribui a $C$ por causa de $B$ ). Uma vez que a causa é o alvo da investigação, as quatro questões se articulam em torno dela: umas buscam saber se há uma causa, outras buscam saber qual é esta causa. Podemos, assim, pensar em uma distinção em pares. Bronstein (2010, p. 108) propôs uma distinção em termos de questões de existência, isto é, questões que buscam constatar se um determinado fato ocorre ou existe (Q1, Q3) e questões de causa e essência, que por sua vez procuram explicar ou definir um dado item $(\mathbf{Q} 2, \mathbf{Q 4})$, ressaltando existir uma correlação entre essas últimas questões - ponto que exploraremos mais adiante. Primeiro, partimos das questões de fato (ou, nos termos de Bronstein, questões de existência) $(\mathbf{Q} 1, \mathbf{Q 3})$ para saber se o objeto de investigação possui um mediador e, caso haja uma resposta afirmativa, passamos às questões de causa e essência $(\mathbf{Q} 2, \mathbf{Q 4})$ para investigar qual é o mediador. 
O conceito aristotélico de definição (ópıouós) é descrito como "o enunciado do o que é" (APo II.10 93b29), e a resposta adequada à pergunta "o que é" nos traz a essência daquilo que buscamos saber. Por um lado, de uma definição (definiens) "não se gera silogismo nem demonstração" (APo II.8 93b 17-20), mas ao realizar uma demonstração, a essência é revelada. Se, anteriormente, Aristóteles já afirmara que procurar pela essência ou procurar pela causa nos leva ao mesmo lugar (APo II.2 90a14, 90a31), ao colocar o modelo em prática em APo II.8 podemos visualizar a equivalência entre definir e explicar ${ }^{3}$.

A começar pela análise do eclipse em APo II.8 93a37: temos eclipse como termo maior $(A)$, e lua como termo menor $(C)$. 0 primeiro passo é saber se há uma causa passível de investigação científica, que seja também o mediador $(B)$ entre os dois termos. Dado que há um eclipse e que há uma causa $(B)$, passamos à segunda etapa da investigação para descobrir por que ocorre eclipse, ou seja, o que é $B$. Neste caso, a causa (B) é a interposição da Terra (93b5). Ao descobrir qual é a causa de eclipse, ao mesmo tempo, descobre-se também a essência dele, e a investigação é concluída ${ }^{4}$. Temos assim:

\section{Silogismo de eclipse:}

Eclipse se atribui a interposição da Terra

Interposição da Terra se atribui à lua

$\therefore$ Eclipse se atribui à lua

Se a definição de eclipse é "interposição da Terra" (93b7) e "interposição da Terra" é a causa de eclipse, causa e essência são o mesmo ${ }^{5}$ (90a 14; 90a 31).

\footnotetext{
${ }^{3} A$ interdependência entre definir e explicar foi minuciosamente explorada por Charles (2000, pp. 245 51). Ver também: Zuppolini (2017, pp. 41-8; Peramatzis (2011 pp. 180-8; 2013).

${ }^{4}$ Ainda que seja um ponto disputado pela literatura, seguimos aqui a interpretação de Charles $(2000$, pp. 23-5) a respeito das etapas da investigação científica aristotélica. Charles propõe como sendo três os estágios da investigação: no estágio 1, o investigador possui uma caracterização de determinado nome, mas ainda não sabe se o item designado por aquele nome genuinamente existe; no estágio 2, o investigador descobre que o item designado por aquele nome existe, porém desconhece sua essência ou causa; no estágio 3 , o investigador finalmente descobre a essência ou causa do item designado por aquele nome e, por fim, a investigação é concluída.

${ }^{5}$ Apesar do modo irregular com que Aristóteles se expressa, a rigor, (i) o termo maior do silogismo deve ser não o definiendum "eclipse", mas "privação de luz" e (ii) a definição completa do eclipse envolve os três termos do silogismo: eclipse é (df.) privação de luz (A) na lua (C) causada pela
} 


\section{0 | XXI Semana Acadêmica do PPG em Filosofia da PUCRS, Vol. 1}

Semelhantemente ocorre com o caso do trovão em APo II.8 93b7-9 e 10 94a5-10. Ambos os exemplos, porém, são casos de processos naturais. Vejamos a seguir como Aristóteles aplica o modelo às substâncias sensíveis.

Como dissemos anteriormente, a aplicação às substâncias sensíveis ocorre apenas a partir de Met. Z.17. Ao compararmos as apresentações em ambos os tratados, a Metafísica possui uma diferença em relação a APo: a introdução da análise hilemórfica e, através dela, a extensão do modelo também aos itens deste tipo. O hilemorfismo de Aristóteles é a ideia de que objetos são compostos constituídos de matéria e forma. A análise de uma substância (e.g.: homem) nesses termos é realizada considerando sua matéria (e.g.: carne, ossos, órgãos do homem) e forma (e.g.: sua alma racional). Como veremos a seguir, somente ao realizá-la é possível que a investigação da essência de substâncias resulte em um explanandum legítimo.

Nesse sentido, a fim de formular explananda legítimos, Aristóteles retoma em Z.17 a preocupação pelo ponto de partida correto: para que a pergunta por que conduza o investigador à causa daquilo que se busca é necessário adotar uma estrutura atributiva, isto é, perguntar sempre "por que um item se atribui a outro" (Met. Z17 1041a 5-11). Quando investigamos processos naturais a estrutura predicativa do explanandum é clara. Porém, quanto às substâncias hilemórficas é

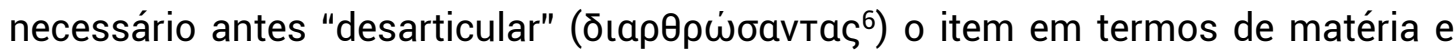
forma, tornando a questão predicativa. Assim, o primeiro passo para a investigação de substâncias é a análise hilemórfica. A respeito de homem, perguntar "por que este corpo possui tal e tal característica?" é procurar a causa de sua matéria ser arranjada desse determinado modo, e a resposta para essa pergunta nos revelará a sua forma - e esta é a essência de homem (1041b 6-9), desse modo, temos:

\section{Silogismo de homem:}

Arranjo desse tipo se atribui a alma racional

alma racional se atribui a esse corpo com tais características

interposição da Terra (B). Ver o exemplo do trovão em 93b7-14 e ver o tipo de definição discutido em 93b38-94a7.

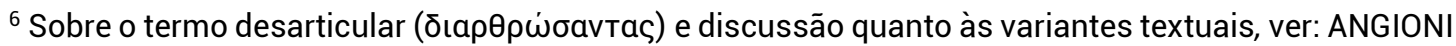
(2008, p. 340) 
$\therefore$ Arranjo desse tipo se atribui a esse corpo com tais características

E, por sua vez, a definição de homem:

Homem $=$ def. corpo estruturado de certo modo com vistas a (ou por causa

de) uma alma racional.

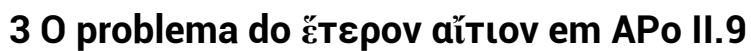

Uma vez que conhecemos o modelo e sua aplicação prática, retornemos aos Analíticos, mais especificamente APo II.9, capítulo em que Aristóteles apresenta uma condição para que essa estrutura seja utilizada:

De algumas coisas, há uma causa diferente, mas, de outras, não há. Por conseguinte, é evidente que, também entre os o que é, alguns são imediatos e são princípios, com relação aos quais é preciso pôr como fundamento tanto que são o caso como o que são, ou fazê-los evidentes de um outro modo (tal como precisamente faz o aritmético: põe como fundamento tanto o que é a unidade, como que ela é o caso); por outro lado, entre os o que é que comportam mediador, isto é, aqueles para os quais a causa da ousia ${ }^{7}$ é diferente, é possível, como dissemos, mostrá-los através de demonstração, sem demonstrar o o que é. (APo II.9 93b21-28, trad. Angioni, 2002, com modificações)

Aristóteles afirma que há itens que possuem e itens que não possuem "causa

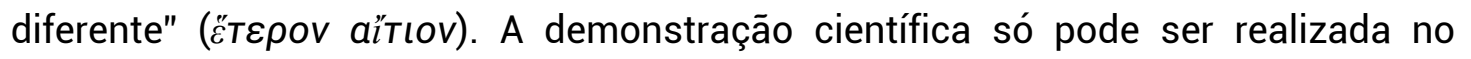
primeiro caso, ou seja, dos itens que possuem "causa diferente". Uma vez que Aristóteles não nos ofereceu exemplos de itens deste tipo, a literatura interpretou a passagem de maneira bastante diversa. A que Aristóteles se refere quando menciona

\footnotetext{
${ }^{7}$ Meu itálico. Algumas considerações sobre o termo ousia, o qual optamos por não traduzir neste capítulo: Tradicionalmente traduzido por "substância", o termo ousia nos tratados aristotélicos possui duas acepções, como observou Angioni (2008): (i) ousia designa os objetos concretos do senso comum; o substrato onde se encontram todos atributos das demais entidades - isto é, as "substâncias"; e (ii) ousia designa a substancialidade de uma entidade, no sentido de ser aquilo que fixa a identidade de um item, sendo o seu fundamento último - ou seja, a essência. Nesta passagem, a distinção se mostra particularmente relevante, na medida em que Charles (2000) e Bronstein (2016) divergem quanto à acepção designada pelo termo em APo II.9. Enquanto, para Charles, ousia aqui designa substância; Bronstein interpreta ousia como essência. Veremos mais adiante os desdobramentos dessas opções, ainda que sem nos comprometermos como uma análise aprofundada desta questão em particular, uma vez que esta foge aos propósitos deste texto.
} 


\section{2 | XXI Semana Acadêmica do PPG em Filosofia da PUCRS, Vol. 1}

"itens que possuem causa diferente"? A restrição oferecida seria uma referência às substâncias sensíveis? De acordo com a leitura desenvolvimentista, a resposta seria afirmativa, e a retomada do modelo na Metafísica seria uma reformulação posterior; por outro lado, a leitura não-restritiva defende que a restrição não seria às substâncias sensíveis, senão que às essências conceitualmente simples - às quais não são passíveis de reorganização em uma estrutura predicativa. A seguir, exploraremos as duas hipóteses interpretativas e suas respectivas soluções para o problema.

\section{Hipótese desenvolvimentista}

Os fundamentos da hipótese desenvolvimentista podem ser estruturados em três principais pontos: i) em primeiro lugar, defende-se que, em APo II.1-2, Aristóteles estabelece uma distinção entre sujeitos e atributos; ii) interpreta-se APo II.9 como evidência da distinção entre essências de atributos e essências de substâncias; iii) por fim, rejeição de Met. Z.17 como uma evidência de que as substâncias sensíveis seriam passíveis de análise pelo modelo explanatório-causal nos APo, partindo da defesa de que a análise hilemórfica está ausente de $A P o$ e, desse modo, seria uma reformulação posterior.

Comecemos pela distinção entre sujeitos e atributos. Os três principais autores desenvolvimentistas - a saber, Ross (1949), Goldin (1996) e Bronstein (2016) - estão de acordo quanto à preocupação aristotélica em realizar tal distinção em APo II. Um primeiro argumento em prol dessa distinção seria notar o alvo do conhecimento científico demonstrativo: explicar por que um atributo pertence a um sujeito. Assim, a distinção entre sujeitos e atributos seria uma característica básica da realidade que precisa estar adequadamente representada em uma investigação e/ou discurso científico (BRONSTEIN, 2016, p. 76-82). Uma vez que APo II se dedica precisamente a esse tipo de conhecimento, seria de fundamental importância saber o modo correto de investigar um e outro.

Ross (1949) estabelece a distinção em termos de "substâncias" e "atributos" (ROSS, 1949, p. 76) e, segundo o autor, essa diferença se faz clara em APo II.2 ao conhecermos a noção de mediador: perguntar por substâncias não se converteria 
em perguntar por um mediador. Se as quatro questões passíveis de investigação se dividem em termos da busca pelo mediador, e perguntar se "determinada substância existe?" ou "o que determinada substância é?" não significaria perguntar pelo mediador, se seguiria que tais questões não são direcionadas a entidades deste tipo, senão a itens que se atribuem a determinadas substâncias. Além disso, o autor argumenta que a existência de uma substância seria algo a ser respondido por observação, enquanto a definição da substância seria respondida em termos de gênero (genus) e diferença (differentia ou differentiae) que a distingue de outras espécies daquele genus. A leitura de Ross é endossada por Goldin - para este, igualmente $A P o$ apresentaria uma divisão entre atributos demonstráveis e o que Goldin chama de "substâncias epistêmicas" - termo usado para designar o substrato mais básico de uma determinada ciência (GOLDIN, 1996, p. 109-10).

Bronstein (2016) estabelece a distinção em termos de atributos demonstráveis e sujeitos-tipo (subject-kinds) ${ }^{8}$. Os sujeitos-tipo são subdivididos em: primários (e.g. unidade, ponto), cuja existência é indemonstrável; e subordinados (e.g. triângulo, ser humano) cuja existência é demonstrável. É incontroverso que sujeitos-tipo primários têm causas idênticas, mas Bronstein enxerga boas razões para considerar que também os subordinados possuam causas idênticas: em APo II.8, apenas atributos demonstráveis têm causas diferentes; uma vez que sujeitostipo subordinados não são atributos demonstráveis, e assumindo que a distinção entre ambos os tipos de causa é exaustiva, se seguiria que sujeitos-tipo subordinados têm causas idênticas (BRONSTEIN, 2016, p. 134). Esse ponto será melhor desenvolvido adiante. Antes disso, é importante destacar que Bronstein faz distinção também entre as essências (BRONSTEIN, 2016, p. 131), e nesta distinção reside sua solução para o problema: há essências causalmente complexas - isto é, que possuem a forma "A-C por causa de B", as quais são descobertas por demonstração - e essências causalmente simples - compostas genus e differentiae e assim descobertas por divisão e indução. Apenas se considerarmos que as substâncias sensíveis (e.g. ser humano) em APo têm essências causalmente

\footnotetext{
${ }^{8}$ Bronstein também propõe uma distinção e reformulação dos estágios de investigação e da ordem em que as perguntas devem ser postas em uma investigação científica. A argumentação é extensa e será deixada de lado nesse texto. Ver: Bronstein (2016, cap. 6-8)
} 


\section{4 | XXI Semana Acadêmica do PPG em Filosofia da PUCRS, Vol. 1}

complexas, estas estariam previstas no domínio de aplicação do modelo e seriam passíveis de demonstração.

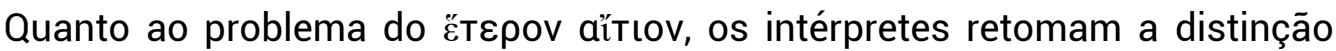
entre sujeitos e atributos, de modo que ao mencionar "causas diferentes" a referência seriam os atributos demonstráveis, cujas causas seriam diferentes deles próprios, enquanto os itens que possuem as mesmas causas ou "causas idênticas" seriam as substâncias, cujas causas seriam idênticas a elas próprias. De acordo com Ross (1949, p. 633), se a causa do ser para a substância é a forma, e a substância é idêntica à forma, substâncias não poderiam ser demonstradas, nem suas causas poderiam ser reveladas por demonstração. Aristóteles, no entanto, permite esse tratamento a certas entidades, as quais têm suas existências consideradas independentes no âmbito de uma ciência particular, embora não sejam substâncias - como é o caso da unidade. Semelhantemente, Goldin defende que APo II.9 ressalta a distinção previamente estabelecida entre atributos demonstráveis, cujas causas são diferentes deles próprios, e as substâncias epistêmicas, cujas causas são as mesmas (GOLDIN, 1996, pp. 129-30).

O ponto de vista de Bronstein é fundamentado na leitura do termo ousia (ov̉oía) em APo Il.9 93b26 como "essência". Assim, ao afirmar que a causa é a mesma ou que a causa é diferente, o referencial seria a essência de um determinado item. $A$ causa de um sujeito-tipo $S$ é a mesma da essência de $S$; já a causa de um atributo demonstrável $P$ é diferente da essência de $P$ - além disso, apenas atributos demonstráveis possuem mediador. O capítulo em questão seria justamente uma evidência dessa leitura, e um argumento em seu favor seria a frequência de ousia designando "essência" em APo II (a saber, II.3, 90b30-1, II.4, 91b9, 2.6, 92a6, II.7, 92a34, 92b13, b14, II.13, 96a34), que seria muito maior em comparação com seu uso para designar "substância" ou mesmo "ser" (BRONSTEIN, 2016, p. 134).

\section{Hipótese não-restritiva}

Em oposição aos desenvolvimentistas, Charles (2000), Peramatzis (2011), e Zuppolini (2017) oferecem às questões suscitadas, com especial enfoque no

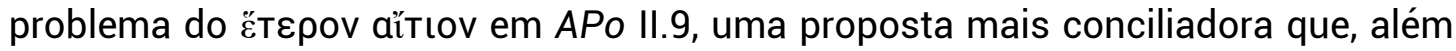


de incluir as substâncias sensíveis no domínio de aplicação do modelo já em APo, realiza também certa aproximação entre Segundos Analíticos e Metafísica. 0 pilar desta hipótese não-restritiva é desconsiderar a distinção entre substâncias e atributos como ponto de partida para compreender o modelo explanatório-causal em APo II.1-2 8-10. Em vez disso, como veremos mais adiante, considera-se o escopo de interesse peculiar a este tratado. Por fim, defende-se nessa leitura que a análise hilemórfica das substâncias estaria prevista no modelo original dos Analíticos, ainda que sem um pleno desenvolvimento deste - ou seja, Met. Z.17 concretizaria uma aplicação já prevista e sugerida em $A P o$, de modo algum implicando em uma reformulação posterior.

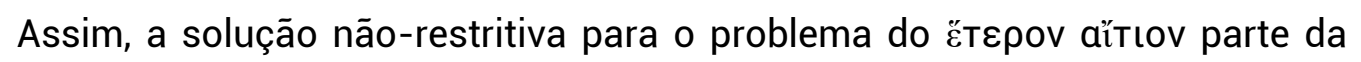
rejeição de que "itens que não possuem causa diferente" seja uma referência direta às substâncias sensíveis, mas uma restrição a outra categoria. Partindo da leitura do termo ousia em 93b26 como "substância", Charles (2000) estabelece a distinção em termos de i) itens que possuem uma causa que é separada daquilo que faz o item ser precisamente o que é, e ii) itens que possuem causas idênticas às suas essências (CHARLES, 2000, pp. 275). A causa investigada é a causa da existência de substâncias (e.g. homem, terra, sol), e o que se busca é a resposta para a questão "por que", a qual nos fornece a essência dessas substâncias (APo II.2 90a 14-15).

De acordo com Peramatzis (2014), "itens que não possuem causa diferente" seria uma referência aos itens que são primeiros e fundamentais - isto é, aqueles itens que são causas de outros, de modo que não haja nada a ser causa deles, nem anterior a eles (PERAMATZIS, 2014, pp. 4-8). 0 autor acrescenta que Aristóteles em momento algum afirma destes itens que eles sejam as suas próprias causas, mas tão somente que não há "outra causa". Desse modo, aquilo para o qual não há "outra causa" são essências que são imediatas e são princípios - e estas essências não são demonstráveis, mas são partes das definições e demonstrações dos itens dos quais são causas. Por exemplo, alma é essência de homem, e a causa que explica precisamente o que homem é, mas não possui ela própria "outra causa" (CHARLES, 2000, p. 278). Se, por um lado, não temos exemplos concretos em APo 


\section{6 | XXI Semana Acadêmica do PPG em Filosofia da PUCRS, Vol. 1}

II. $9^{9}$, Charles argumenta que os livros centrais da Metafísica esclarecem a questão ao exemplificar o modelo a partir de "homem": "homem" e "essência do homem" serão diferentes, pois "homem" faz parte da classe de entidades compostas - mais especificamente, um composto hilemórfico -, o que significa que sua essência (forma) é algo distinto que mantém o composto unido e coeso (CHARLES, 2000, pp. 277-8).

Seguindo esta linha interpretativa, Zuppolini defende que a exceção em APo II.9 parecem ser entidades cuja essência seria conceitualmente simples (ou seja, cuja essência não pode ser captada pela articulação de conceitos em uma estrutura triádica), e não propriamente os compostos hilemórficos. Além disso, o autor argumenta que não há nada que comprove a exclusão das substâncias, enquanto há evidências favoráveis à sua inclusão: além de "homem" e "alma" serem apresentados como exemplos (APo II.8 93a22-4), ao afirmar que Q3 (S existe?) e Q4 (o que é S?) também são respondidas pela investigação do mediador (APo II.2 89b37-90a5), subtende-se que a essência de sujeitos de certo modo também deveria ser revelada por demonstração - e isso efetivamente ocorre em Met. Z.17 e H.2-4 (ZUPPOLINI, 2017, p. 133-7). A retomada do modelo na Metafísica, assim, não seria uma reformulação posterior, senão que a consolidação de um projeto que já estava presente nos Analíticos.

Por fim, quanto à delimitação do escopo dos Analíticos, nesta leitura nãorestritiva defende-se que a preocupação aristotélica em $A P o$ não seria aprofundamento em questões metafísicas, senão linguísticas, predicativas, ou relacionadas a problemas epistemológicos (PERAMATZIS, 2011 p. 211; 2014, p.8). Nesse sentido, a omissão das substâncias hilemórficas ocorreria porque projeto dos Analíticos é outro, sem necessariamente implicar em uma consequência dramática - como sua exclusão do domínio de aplicação do modelo, tampouco em um salto temporal entre APo e Metafísica.

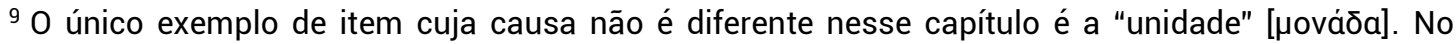
entanto, unidades não são propriamente substâncias, e o exemplo parece indicar que a restrição seja direcionada a entidades causalmente simples (Zuppolini, 2017, p. 133-5), ou, como Charles (2000, 277-8) defende, itens primários (e.g. alma) e itens derivados destes (cujas definições seriam compostas, e.g. homem). Essa questão está longe de ser incontroversa, ver: Charles (2000, p. 278).
} 


\section{Conclusão}

O modelo explanatório-causal de Aristóteles, elaborado em Segundos Analíticos II.8-10, permite descobrir a essência pela causa a partir de uma estrutura triádica. Esse modelo, no entanto, não possui um domínio de aplicação irrestrito: são passíveis de análise nesses termos apenas os itens que possuem "causa diferente". A restrição, porém, é apresentada em APo II.9 sem explicitar quais são os itens que se encaixam nessa descrição. Uma vez que nos Analíticos são utilizados como exemplos apenas processos naturais, a omissão das substâncias sensíveis gerou divergências entre os intérpretes.

Procuramos estruturar tais divergências em duas linhas interpretativas: i) a leitura restritiva ou desenvolvimentista e ii) a leitura não-restritiva. A primeira hipótese parte de uma distinção fundamental entre substâncias e atributos demonstráveis (desde APo II.1-2, e mais explicitamente em APo II.9), e defende que as substâncias não haviam sido previstas quando da elaboração dos Analíticos, sendo admitidas posteriormente na Metafísica, em virtude de uma reformulação do modelo - isto é, do acréscimo da análise hilemórfica. A segunda hipótese, por sua vez não-restritiva, propõe uma leitura que concilia os projetos dos Analíticos e da Metafísica, ao desconsiderar que a retomada do modelo na Metafísica representa uma reformulação tardia, senão que a concretização de um projeto já existente em $A P o$, ainda que não devidamente explorado neste tratado. De acordo com esta hipótese, omitir as substâncias sensíveis de uma análise aprofundada não seria um sinal de que Aristóteles ainda não desenvolvera sua teoria do hilemorfismo, mas tão somente causada por economia argumentativa - o escopo investigativo dos Analíticos isentaria Aristóteles de se comprometer com teorias que serão adequadamente respondidas na Metafísica. Esta segunda hipótese nos parece

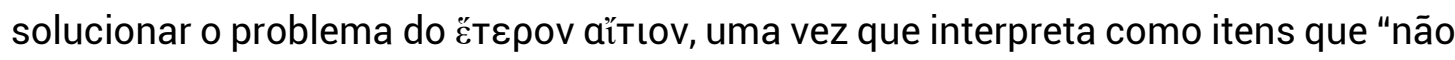
possuem causa diferente", noções como as essências conceitualmente simples, as quais não são passíveis de uma reorganização em uma estrutura predicativa. Sem implicar em uma leitura que torne incompatíveis os projetos da Metafísica e dos Analíticos. 


\section{8 | XXI Semana Acadêmica do PPG em Filosofia da PUCRS, Vol. 1}

\section{Referências bibliográficas}

ANGIONI, L. Aristóteles: Metafísica, livros VII e VIII. Tradução e notas. 2 ed. Campinas: Instituto de Filosofia e Ciências Humanas da Unicamp, col. Clássicos da Filosofia: Cadernos de Tradução n.11, 2005.

ANGIONI, L. Aristóteles: Segundos Analíticos: Livro II (tradução). Campinas: IFCH/UNICAMP. Clássicos da Filosofia: Cadernos de Tradução nº 4, 2002.

ANGIONI, L. As noções aristotélicas de substância e essência. Campinas: Editora Unicamp, 2008.

ANGIONI, L. Lógica e Ciência Em Aristóteles. Lucas Angioni (Ed.). Campinas: Editora PHI, 2014.

BARNES, J. Aristotle: Posterior Analytics. Translated with a commentary. 2nd edition. Oxford: Clarendon Press, 1993.

BASTOS, D. A Teoria da Demonstração Científica de Aristóteles em Segundos Analíticos 1.2-9 e 1.13. Archai 30, 2020.

BRONSTEIN, D. Aristotle on Knowledge and Learning: The Posterior Analytics. Oxford: OUP, 2016.

BRONSTEIN, D. Investigação e Paradoxo do Mênon: Aristóteles, Segundos Analíticos II 8. Dois Pontos 7 (3): 107-130, 2010.

CHARLES, D. Aristotle on Meaning and Essence. Oxford: Oxford University Press, 2000.

CHARLES, D. Definition and Explanation in the Posterior Analytics and Metaphysics. In: Charles, D (ed.), Definition in Greek Philosophy, 286-328. Oxford: OUP, 2010.

CHARLES, D. Matter and Form: Unity, Persistence, and Identity In: Unity, Identity, and Explanation in Aristotle's Metaphysics, edited by T. Scaltsas, D. Charles \& M.L. Gill, 75-105. Oxford: Oxford University Press, 1994.

GOLDIN, O. Explaining an Eclipse: Aristotle's Posterior Analytics 2.1-10. Ann Arbor: University of Michigan Press, 1996.

PERAMATZIS, M. Aristotle's Hylomorphism: The Causal-Explanatory Model Metaphysics. 1(1):12-32, 2018. Disponível em:

<https://metaphysicsjournal.com/articles/10.5334/met.2/\#>. Acesso em: 2 de agosto de 2021. 
PERAMATZIS, M. Matter in Scientific Definitions in Aristotle. In: Oxford Handbooks Online. New York: OUP, 2014. Disponível em:

<https://www.oxfordhandbooks.com/view/10.1093/oxfordhb/9780199935314.001. 0001/oxfordhb-9780199935314-e-001 >. Acesso em: 2 de agosto de 2021.

PERAMATZIS, M. Priority in Aristotle's Metaphysics. Oxford: Oxford University Press, 2011.

PERAMATZIS, M. Science and Metaphysics in Aristotle's philosophy. Metascience 22 (2): 303-315, 2013.

PERAMATZIS, M. What is a form in Aristotle's hylomorphism? History of Philosophy Quarterly, Vol. 32, No. 3 (JULY 2015), pp. 195-216, 2015.

ROSS, D. Aristotle's Metaphysics: A Revised Text with Introduction and Commentary. 2 volumes. Oxford: Clarendon Press, 1924.

ROSS, D. Aristotle's Prior and Posterior Analytics: A Revised Text with Introduction and Commentary. Oxford: Clarendon Press, 1949.

ZINGANO, M. (org.) Sobre a Metafísica de Aristóteles. São Paulo: Odysseus. 2005.

ZUPPOLINI, B. Aristotle's Foundationalism. Revista Dissertatio de Filosofia, 44, 187$211,2016$.

ZUPPOLINI, B. Fundacionalismo e Silogística. In: Lógica e Ciência Em Aristóteles. Lucas Angioni (Ed.). Campinas: Editora PHI, 2014.

ZUPPOLINI, B. Ontological Underpinnings of Aristotle's Philosophy of Science. Tese de Doutorado em História da Filosofia Antiga. Campinas: Unicamp, 2017. 